\title{
Salient Attributes of Urban Green Spaces in High Density Cities: The Case of Hong Kong
}

\begin{abstract}
This study aimed to elicit users' perceptions of key attributes of urban green spaces (UGS) in Hong Kong, a compact and land-hungry city, and assess their associations with perceptions of the usefulness, quality, and the frequency of visits in a sample of users of these spaces. This study first employed the repertory grid technique to interviews with 21 respondents to elicit users' assessment of key attributes of green spaces. Second, the factors that emerged were used to develop a questionnaire, which was administered telephonically to 263 individuals who were users of these spaces. The responses were then analysed by multiple regression to assess the extent to which the attributes predicted users' attitudes regarding usefulness and quality and users' behaviour regarding frequency of use of the spaces. The results suggested that the four factors of attributes (features, naturalness, accessibility, and variety of facilities) significantly predicted both of the attitudes and the behaviour relevant to UGS in Hong Kong. Accessibility was most important to the frequency of use and features were the most important to attitudes regarding usefulness and quality. The results imply that policymakers and urban planners could more effectively and sustainably utilise limited land resources by considering users' nuanced meanings and perceptions of urban green spaces. Limitations of the study and future research directions are discussed.
\end{abstract}

Keywords: repertory grid; features; naturalness; accessibility; variety of facilities

\section{Introduction}

Hong Kong is one of the most densely populated cities in the world, averaging 6,544 persons per square kilometre (Census and Statistics Department, 2011). More than 80\% of its total area is hilly terrain which is unfavourable for urban development (A. Y. Lo \& Jim, 2012; Ye, 1998), this physical limitation squeezed the urban areas into approximately $24 \%$ of its total land (Planning Department, 2013). Hong Kong is therefore a high density and 'land-hungry' city (Tang, Wong, \& Lee, 2007). Despite this, the government acknowledged the importance and positive aspects of urban green spaces (UGS), such as their contribution to relieving psychological stress and the enhancement of the physical well-being of residents (Planning Department, 2005). In Hong Kong, there are 25 square kilometer zoned for open spaces, this occupies a significant proportion $(9 \%)$ of the developed land area of the city (Planning Department, 2013). In the global context, compared to cities of similar size, Hong Kong's proportional provision of UGS is among the lowest in the world (A. Y. Lo \& Jim, 2012; P. Y. Tan, Wang, \& Sia, 2013). 
Previous research had examined some important characteristics of UGS, such as park facilities and features, park maintenance, distance, size, and perceived safety (Bedimo-Rung, Mowen, \& Cohen, 2005; Giles-Corti et al., 2005; Van Herzele \& Wiedemann, 2003). Although these characteristics were found to be important factors influencing the use of UGS, some studies disagree (Schipperijn, Bentsen, Troelsen, Toftager, \& Stigsdotter, 2013). For example, A. Y. Lo and Jim (2010) found that the quality of UGS was not correlated with the frequency with which individuals visited them; Schipperijn, Stigsdotter, Randrup, and Troelsen (2010) found no reliable socioeconomic, size, or travel distance predictors of visitation frequency to the most often used UGS. These inconsistent results may be due to cultural differences among cities. Tang and Wong (2008) suggested that the concept of UGS depends on a given city's cultural context. For example, in Hong Kong, UGS are broadly defined to include parks, gardens, playgrounds, and sitting-out areas (Koon Kwai Wong, 2009) of vegetated and open spaces within the city's limits (A. Y. Lo \& Jim, 2010). Moreover, the lack of consensus on desirable UGS planning criteria regarding location, quantity, and use may be related to the contextual and cultural diversity among cities (Maruani \& Amit-Cohen, 2007). In addition, previous studies have also neglected the complexity of users' psychological evaluation of UGS (Wang, Brown, Liu, \& Mateo-Babiano, 2015), focusing instead on socioeconomic variables and intrinsic park features (Grove et al., 2006). Thus, while we have some understanding of UGS characteristics, a knowledge gap exists regarding users' psychological preferences on UGS attributes, particularly in high-density cities, such as Hong Kong.

Therefore, cultural differences regarding UGS may be accounted for by gaining a better understanding of the preferences of a given city's residents for their UGS. Policy makers and city planners would likely benefit from such a perspective, which could help them to develop reasoned understandings of the culturally specific needs and preferences of a city's residents (Schipperijn, Stigsdotter, et al., 2010). This study's goals were to identify the salient attributes of Hong Kong's UGS from the perspectives of its residents and then assess the extent to which those attributes mattered to users' attitudes and behaviour towards UGS. In this study, attributes are defined as UGS features or qualities psychologically perceived by users (e.g. the perceived adequacy of facilities, the perceived level of accessibility), and the salience of these attributes is based on the extent to which the attributes influence the users' attitudes and behaviour toward the UGS. Thus, the study aims to accomplish three objectives:

- identify the salient attributes of UGS in Hong Kong;

- examine the ways that these attributes influence users' attitudinal evaluations and behaviours; and 
- discuss the policy implications and offer suggestions for the planning, management, and design of UGS.

\section{Literature Review}

Users appreciate UGS if they are well maintained and able to fulfil specific inhabitants' needs within the city (Bonnes, Passafaro, \& Carrus, 2011; Burgess, Harrison, \& Limb, 1988). They should be open and accessible to the public, well equipped and maintained, and offer opportunities for both social and physical activities. Bonnes et al. (2011) argued that missing features may lead to users' complaints and dissatisfaction. Chiesura (2004) and Shan (2014) studied motives and emotional dimensions of experience from the perspectives of users, through predetermined variables such as use for sport, relaxation, meditation. Certain design attributes such as amenities, perceived usefulness, accessibility (S. Lo, Yiu, \& Lo, 2003) were suggested to be part of most users' preferences and, subsequently, their use of UGS. Lo and Jim (2012) found that Hong Kong citizens preferred high level of greenery, more seats and large UGS.

Accessibility, size, facilities, naturalness and safety are the key attributes of UGS identified by previous studies. Distance is an important attribute influencing the use of UGS (Giles-Corti et al., 2005; Grahn, 1994; C. Lee \& Moudon, 2008; Van Herzele \& Wiedemann, 2003). However, Wang et al. (2015) argued that current planning models have simplistically been using physical proximity in measuring accessibility, and the study found that perceived access is more important than geographic proximity. Van Herzele and Wiedemann (2003) suggested that distance and size criteria should be considered simultaneously because people are willing to trade proximity for size of UGS (Poudyal, Hodges, \& Merrett, 2009). In addition, facilities are important attributes to support users' activities in UGS (Carr, 1992; Giles-Corti et al., 2005; Kaczynski, Potwarka, \& Saelens, 2008; Van Herzele \& Wiedemann, 2003). The facilities and their conditions (e.g. maintenance and quality) influence users' preference in choosing UGS (A. Lee \& Maheswaran, 2011). Provision of variety of facilities can satisfy various groups of users because of their different purposes to use UGS (Jay \& Schraml, 2009; Sanesi \& Chiarello, 2006; Shan, 2014). Besides, living in green environment, people are more likely to have better physical health (De Vries, Verheij, Groenewegen, \& Spreeuwenberg, 2003) and psychological health (Grahn \& Stigsdotter, 2010). People desire to contact and experience natural environment (Bonnes et al., 2011; Burgess et al., 1988; Van den Berg \& Ter Heijne, 2005). Natural features, e.g. trees, birdlife, water, are needed for UGS (Chiesura, 2004; Coley, Sullivan, \& Kuo, 1997; Giles-Corti et al., 2005). Schipperijn, Ekholm, et al. (2010) and Chiesura (2004) suggested that natural setting in UGS provides experience of quietness and peacefulness to users which motivates users to visit UGS (Coles 
\& Bussey, 2000; Shan, 2014). Finally, perceived safety in UGS is operationalized as presence of lighting, visibility of surrounding houses or roads, type of surrounding roads, and presence of crossings (Giles-Corti et al., 2005). Van Herzele and Wiedemann (2003) argued that the safety level is a basic condition to determine whether users would visit a particular UGS. Therefore it is essential to plan and design a green and safe environment (Luymes \& Tamminga, 1995).

Although the above attributes were identified in the prior studies, there is no comprehensive list of important attributes regarding individuals' psychological considerations regarding UGS (Home, Bauer, \& Hunziker, 2010). Previous studies tend to use objective measures, such as expert assessment or geographic information system (Hillsdon, Panter, Foster, \& Jones, 2006; Lafortezza, Carrus, Sanesi, \& Davies, 2009; Van Herzele \& Wiedemann, 2003). However users' evaluations could be different from the expert opinions (Coles \& Bussey, 2000). Scott, Evenson, Cohen, and Cox (2007) suggested that users' perceptions are better predictors of behaviour than objectively measured environmental factors and Kaczynski, Potwarka, Smale, and Havitz (2009) found that objective and subjective assessments did not correlate closely. However, Hur, Nasar, and Chun (2010) suggested that the relationship between UGS' physical characteristics and overall evaluations of the environment is mediated by users' perceptions. In other words, subjective factors are associated with objective factors through users' perceptions (Schipperijn, Stigsdotter, et al., 2010). In addition, previous studies have generally relied on structured surveys that may have ignored factors that individuals use when they evaluate and compare among UGS. Coshall (2000) suggested that understanding individual preferences is important because, for example, although natural features are often employed in UGS studies, the meaning of 'natural features' may vary among users. Naturalness may refer to green elements, wildlife, clean air, and/or a sense of peacefulness to varying extents, singly or in some combination. Therefore, less structured ways to tap into users' perceptions and preferences could be a more valid method of identifying the salient UGS attributes held by users (Olson \& Muderrisoglu, 1979). From this perspective, in addition to planning physical adaptations to UGS, planners and managers should consider users' subjective assessments.

\section{Methods}

\subsection{Repertory grid interviews}

Kelly (1955) developed the Repertory Grid Technique (RGT) primarily for use in the field of clinical psychology. This instrument allows patients to elicit personal propositions in their own words and to explain how they make sense of the world. The process of unfolding these 
hidden constructs helps clinicians to develop a deeper understanding of individuals' thoughts and behaviours. RGT has been extended from psychology into other fields to help identify personal constructs in other domains, such as organizational behaviour (Huang, Wright, Chiu, \& Wang, 2008; Wright, 2008), travel and tourism (Coshall, 2000; Lawton, 2005), and environmental studies (Home et al., 2010). Although RGT was originally designed for application on an individual basis, contemporary studies have demonstrated its feasibility for analysing group data (Fransella, Bell, \& Bannister, 2004; Jankowicz, 2005), and this serves as an alternative method of qualitative research.

Kelly (1955) argued that individuals construct systems that often are unarticulated or implicit, which makes elaboration of these constructs difficult. Therefore it may not be effective to directly ask respondents to describe and explain their opinions through interviews or focus groups. The instrument assumes that a mental model is a 'construct system', defined as 'a way in which things are construed as being alike and yet different from others (p.105)' (Kelly, 1955). Therefore, a construct is expected to be bipolar or dichotomous in nature, e.g., good and bad, pretty and ugly. Individuals learned from their experiences to understand how the world works and the way that an individual understands his or her personal reality is built from contrasts rather than absolutes (Jankowicz, 2005; Kelly, 1955). Therefore, for example, it would be difficult for users to describe how a UGS provide adequate facilities, but users are more able to identify the differences among different UGS in terms of adequacy of facilities.

Pike (2003) pointed out in his study on travel that the sample size necessary to use RGT can be relatively small and that, in a given target population, continual sampling is recommended until such samples reveal no new constructs. RGT has commonly been used in exploratory and qualitative research with sample sizes of about 20 (Home et al., 2010; Huang et al., 2008; Pike, 2003; Wright, 2008).

\subsubsection{Element Selection and Elicitation}

In RGT, elements refer to the objects or stimuli that are important in a research study; example of elements in previous relevant studies are tourist attractions (Coshall, 2000), leaders and subordinates (Huang et al., 2008), food products (Thompson, 2002), and organisations (Daniels, Johnson, \& de Chernatony, 2002). Elements can be chosen by the researchers or provided by the respondents (F. B. Tan \& Hunter, 2002). Reger (1990) suggested that supplying elements to the respondents allows the investigators to compare responses based on a fixed set of elements. For example, Coshall (2000) provided 11 museums and galleries as elements when aiming to understand tourists' images of travel destinations. However, when respondents provide the elements, the relevance of the elements 
might be enhanced because respondents would be expected to provide elements that are the most relevant to them. For example, Huang et al. (2008) asked respondents to name nine colleagues (the elements) in a study of the relationship between leaders and members in organisational context.

The present study asked respondents to provide their own elements because there are more than 1,500 UGS in Hong Kong (Leisure and Cultural Services Department, 2007) and, consequently, it was not practical to identify a common list of UGS for which the interviewees had visited. During the interviews, each respondent was given nine descriptors for UGS elicitation. Seven pilot interviews with UGS users (who were not part of the study) revealed eight descriptors that generally presented their perceptions of UGS. The ninth descriptor, 'An Ideal Urban Green Space', represents an exemplar element that is widely used in RGT interviews to facilitate comparisons made by respondents (Home et al., 2010; Huang et al., 2008). The nine descriptors were:

E1: A Good Quality Urban Green Space

E2: An Average Quality Urban Green Space

E3: A Bad Quality Urban Green Space

E4: An Urban Green Space I Visit Most Often

E5: An Urban Green Space I Visit Sometimes

E6: An Urban Green Space I Visit Least Often

E7: A Large Urban Green Space

E8: A Small Urban Green Space

E9: An Ideal Urban Green Space

The respondents were asked to recall eight different UGS that they had visited in the past six months and then assign one of the eight descriptors (E1 through E8) to each of the UGS they had identified. The respondents were told not to assign E9 ('An Ideal Urban Green Space') to any of the UGS they had visited. They were instructed to imagine an ideal urban green space that could be in this category.

\subsubsection{Construct Elicitation}

Dyad or triad approaches are commonly used for the elicitation of constructs. The primary difference between the two approaches is whether the interviewees are asked to compare two or three elements each time. However, this study used the Triad Card Method (Fransella et al., 2004) for construct elicitation because triad comparisons allow elicitation of more cognitively complex constructs (Reddy \& Caputi, 1999). 
First, each interviewee was presented the nine UGS identified in groups of three. Second, the interviewee was asked, 'In what way are any two of these similar, but different from the third?' A typical response was in the form of a construct such as, 'these two are similar because they are quiet, whereas that one is different because it is noisy'. In this case, the bipolar construct 'quiet and noisy' emerged as the 'construct system' defined by Kelly (1955). The elicited constructs were used as the salient attributes with which the respondents evaluated and compared among their chosen UGS. Then, the interviewee was asked the same question for at least six different combinations of the UGS. An example is shown in Table 1. 
Table 1 An Example of a Completed Repertory Grid

\begin{tabular}{|c|c|c|c|c|c|c|c|c|c|c|}
\hline \multirow[t]{2}{*}{ Construct } & \multicolumn{9}{|c|}{ Element (E) } & \multirow[t]{2}{*}{ Contrast } \\
\hline & E1 & E2 & $\mathbf{E 3}$ & E4 & E5 & E6 & E7 & E8 & E9 & \\
\hline sufficient seating & $\checkmark$ & $\checkmark$ & & & & & & & & insufficient sitting \\
\hline $\begin{array}{l}\text { provision of ancillary } \\
\text { facilities, e.g. } \\
\text { washroom, drinking } \\
\text { machine }\end{array}$ & & & & & $\checkmark$ & $\checkmark$ & & & & $\begin{array}{l}\text { No provision of } \\
\text { ancillary facilities }\end{array}$ \\
\hline $\begin{array}{l}\text { Lots of green features, } \\
\text { e.g. trees, greenfield }\end{array}$ & & & & & & & $\checkmark$ & & $\checkmark$ & Few green features \\
\hline Clear division of areas & $\checkmark$ & & & $\checkmark$ & & & & & & $\begin{array}{l}\text { Unclear division of } \\
\text { areas }\end{array}$ \\
\hline $\begin{array}{l}\text { wide range of facilities; } \\
\text { suitable for all ages }\end{array}$ & & $\checkmark$ & & & & & & $\checkmark$ & & $\begin{array}{l}\text { narrow range of } \\
\text { facilities }\end{array}$ \\
\hline Uncrowded & & & $\checkmark$ & & & $\checkmark$ & & & & Crowded \\
\hline
\end{tabular}

Note: The highlighted cells of each row show examples of triad comparison. $\checkmark$ indicates two similar elements identified by the respondent.

\subsubsection{Data Reduction}

Cammock, Nilakant, and Dakin (1995) suggested that constructs can be expressed in group perceptions through data reduction. The data were reduced based on three data reduction criteria: (i) repeated constructs; (ii) unclear bipolarity; and (iii) ambiguous and vague schemas. Two expert raters were invited to participate in the data reduction process, as proposed by Cammock et al. (1995), and they were separately asked to group the elicited 
constructs that they believed had similar or repeated meanings and to remove the constructs that they believed did not have clear bipolarity and schemas. All of the disagreements between the raters about which constructs should be grouped and which constructs should be removed were discussed between them until consensus was reached.

\subsection{Questionnaire development}

The constructs elicited from the RGT interviews were used to develop questionnaire items for survey respondents. For example, a construct of sufficient seating versus insufficient seating was formulated into the questionnaire item statement, 'The urban green space provides

sufficient seating'. The respondents rated the items (attributes of UGS that they had visited) on a seven-point Likert scale where seven indicated the most positive view and one indicated the most negative view. The ultimate goal was to examine the relationships of the constructs to outcome variables. The dependent variables were usefulness, perceived quality, and frequency of visits because these attributes of urban open spaces have been found in previous studies to influence users' attitudes and behaviours (Bonnes et al., 2011; Giles-Corti et al., 2005; Schipperijn, Stigsdotter, et al., 2010). Usefulness and perceived quality were attitudinal measures developed by Balram and Dragićević (2005) and Bonnes et al. (2011). The frequency of visits was adapted from (Schipperijn, Ekholm, et al., 2010) to measure the behavioural aspect. In addition, questions about demographic characteristics (e.g. gender, age, educational level, and monthly income) were included in the questionnaire.

\subsection{Telephone survey}

The questionnaire was administered as a telephone survey conducted between 6 p.m. and 10 p.m. on weekdays using computer-assisted telephone interviews. All Hong Kong residents aged 18 and older were defined as the target population. Telephone numbers were selected randomly by the computer system from residential telephone directories that were produced by a local telecommunication service provider. When telephone contact was successfully established with a target household, one person aged 18 or older was randomly selected from the household members that were present and available using the 'next birthday' rule.

\subsection{Data analysis}

Factor analysis, a principal components analysis with Varimax rotation was used to group the constructs from RGT into a smaller number of interpretable underlying factors. The suitability of the data to factor analysis was assessed by the Kaiser-Mayer-Olkin (KMO) measure of sample adequacy and by Bartlett's test of sphericity (Hair, Black, Babin, \& 
Anderson, 2013). Variables were considered as highly loaded and salient to the interpretation of a factor when the loadings were larger than 0.4 (Field, Miles, \& Field, 2012).

Three multiple regression analyses on the dependent variables (usefulness, perceived quality, and frequency of visits) were performed to determine the extent to which the factors identified in the factor analysis (independent variables) influenced the dependent variables. The extent of influence was evaluated by $t$-statistics, standardized coefficients (beta $(\beta)$ ), and the total variation in the dependent variables explained by the independent variables as measured by the coefficient of determination $\left(\mathrm{R}^{2}\right)$.

\section{Results}

The RGT interviews with UGS visitors were conducted in in eight separate districts of Hong Kong. Following the RGT Triad Card Method, 131 constructs were elicited from 21 respondents. In the data reduction process, the two raters reached consensus on 26 resultant constructs by eliminating ambiguous constructs and consolidating similar or repeated constructs. The inter-rater reliability was $91.6 \%$. The RGT sample consisted of 9 males and 12 females, 15 of which were younger than 30 and 6 of which were 30 or older. The respondents' educational levels ranged from secondary to bachelor's degree level.

A questionnaire consisting of statements of the 26 constructs elicited from the RGT interviews, items that measure the three dependent variables, and demographic background questions was developed (Appendix 1). Altogether, 263 valid responses were collected from the telephone survey for a response rate of $12 \%$. The sample profile and the corresponding population profile are presented in Table 2. The characteristics of the sample used in this study are generally similar to the characteristics of the Hong Kong population regarding gender, age and monthly income, but high educational attainment was over-represented in the sample (Census and Statistics Department, 2011). 
Table 2 Respondent Profile of Telephone Survey

\begin{tabular}{lccc}
\hline Demographic Variable & Sample (N) & Sample (\%) & Population (\%) \\
\hline Gender & & & \\
Male & 105 & $41.06 \%$ & $46.71 \%$ \\
Female & 155 & $58.94 \%$ & $53.29 \%$ \\
\hline Age & & & \\
$18-24$ & 36 & $13.69 \%$ & $10.45 \%$ \\
$25-34$ & 42 & $15.97 \%$ & $18.07 \%$ \\
$35-44$ & 48 & $18.25 \%$ & $18.92 \%$ \\
$45-54$ & 62 & $23.57 \%$ & $21.49 \%$ \\
$55-64$ & 48 & $18.25 \%$ & $15.38 \%$ \\
$>=65$ & 27 & $10.27 \%$ & $15.69 \%$ \\
\hline Education Level & & & \\
Primary & 30 & $11.41 \%$ & $37.60 \%$ \\
Secondary & 128 & $48.67 \%$ & $41.38 \%$ \\
Post-secondary & 105 & $39.92 \%$ & $21.02 \%$ \\
\hline Personal Monthly Income $(\boldsymbol{H K} \$)$ & & & \\
$<10 \mathrm{~K}$ & 119 & $45.25 \%$ & $39.98 \%$ \\
$10-20 \mathrm{~K}$ & 65 & $24.71 \%$ & $32.87 \%$ \\
$20-30 \mathrm{~K}$ & 30 & $11.41 \%$ & $12.01 \%$ \\
$30-40 \mathrm{~K}$ & 16 & $6.08 \%$ & $6.10 \%$ \\
$>40 \mathrm{~K}$ & 28 & $10.65 \%$ & $9.05 \%$ \\
refused to answer & 5 & $1.90 \%$ & \\
\hline & & &
\end{tabular}

4.1 The salient attributes of urban green spaces

The results of the factor analysis grouped the 26 constructs from the RGT into four factors (Table 3 ) that could be retained for further analysis. The KMO was 0.947 and the $p$-value of Bartlett's test of sphericity was .000 ; thus, the data were suitable for factor analysis. The Cronbach's alpha for all the four factors is larger than .70, indicating acceptable reliability of the items grouped into the variables (Hair et al., 2013). 


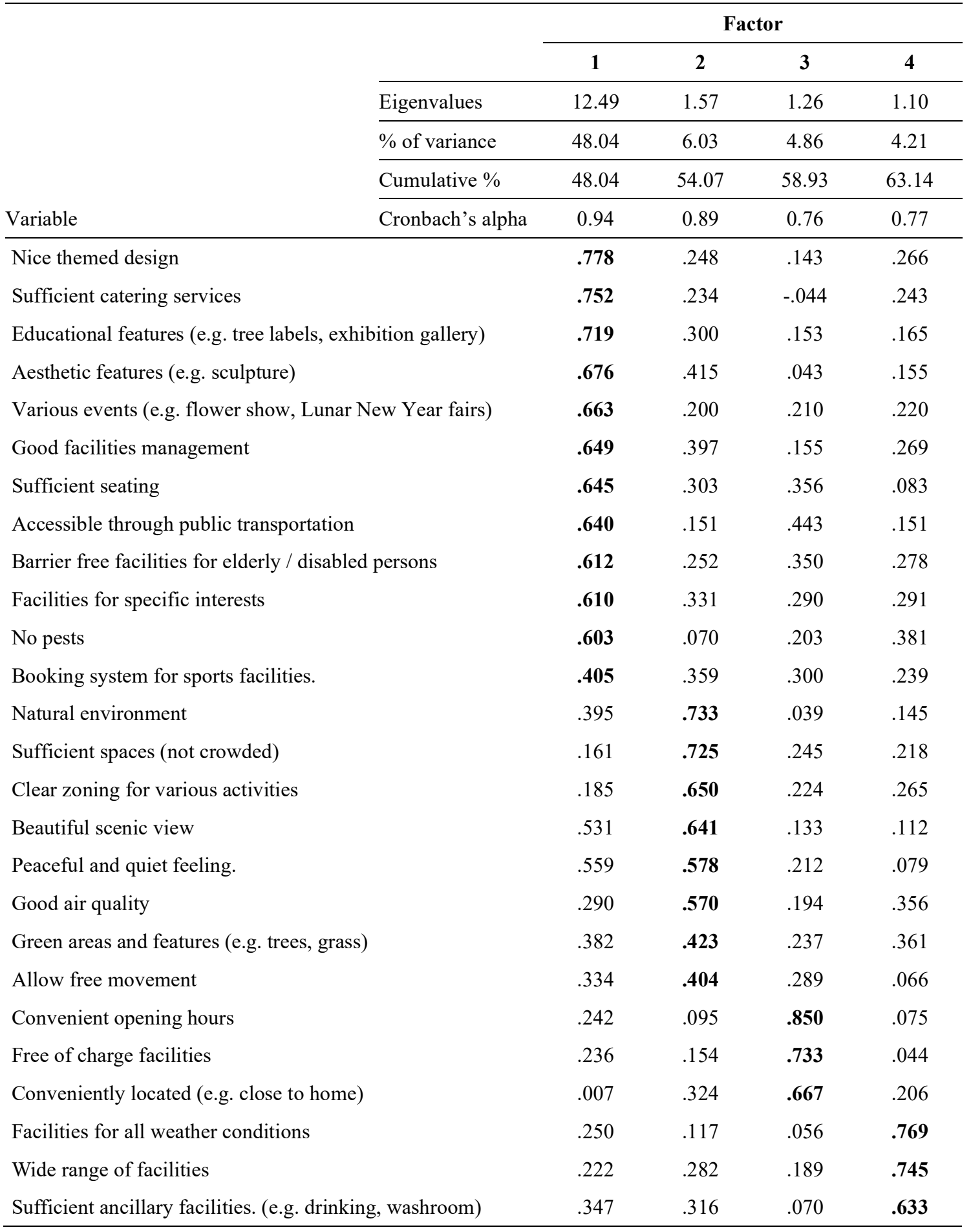


The items that loaded highly on the first factor are about aspects of design, facilities, and the management of UGS, and that factor was termed 'Features'. Features in this study are defined as a user's evaluation of how well the UGS are provisioned and managed. The second factor included items such as scenic view, green features, air quality, and sufficient space. This factor is termed 'Naturalness' and it signifies the extent of the respondents' beliefs about the extent of natural settings with vegetation and other natural elements in UGS. The third factor, 'Accessibility,' consists of items regarding hours of operation (access), location, and fees to use the UGS. Conceptually, Accessibility refers the extent to which the respondents perceive the use of UGS as personally convenient, appropriately located for their personal use, and reasonably priced. The fourth factor was termed 'Variety of Facilities' because its items are about the range of facilities under various weather conditions and ancillary facilities. The Variety of Facilities factor concerns the extent to which a respondent believes that UGS provide different types of facilities for different purposes and conditions.

4.2 The influence of attributes of urban green spaces on users' attitudes and behaviours

The Cronbach's alpha of the three dependent variables (usefulness, perceived quality, and frequency of visits) and the results of the three multiple regression analyses are presented in Table 4. The four factors identified from the RGT interviews accounted for $53 \%, 59 \%$, and $16 \%$ of the variation in usefulness, perceived quality, and frequency of visits, respectively. All of the independent variables made statistically significant contributions. The results suggested that perceptions of features, naturalness, accessibility, or variety of facilities increased, perceptions of usefulness and quality increased and the frequency of visits increased.

Table 4 The impact of key attributes of urban green spaces

\begin{tabular}{|c|c|c|c|c|c|c|c|c|c|}
\hline & \multicolumn{3}{|c|}{$\begin{array}{c}\text { Usefulness } \\
\alpha=0.87\end{array}$} & \multicolumn{3}{|c|}{$\begin{array}{l}\text { Perceived Quality } \\
\qquad \alpha=0.84\end{array}$} & \multicolumn{3}{|c|}{$\begin{array}{l}\text { Visit Frequency } \\
\qquad \alpha=0.78\end{array}$} \\
\hline & $\beta$ & $t$ & $p$ & $\beta$ & $t$ & $p$ & $\beta$ & $t$ & $p$ \\
\hline Features & .470 & 10.94 & .000 & .470 & 11.77 & .000 & .220 & 3.86 & .000 \\
\hline Naturalness & .333 & 7.77 & .000 & .341 & 8.53 & .000 & .156 & 2.73 & .007 \\
\hline Accessibility & .359 & 8.37 & .000 & .401 & 10.05 & .000 & .226 & 3.96 & .000 \\
\hline Variety of facilities & .260 & 6.06 & .000 & .281 & 7.03 & .000 & .196 & 3.44 & .001 \\
\hline $\mathrm{R}^{2}$ & & 0.53 & & & 0.59 & & & 0.16 & \\
\hline
\end{tabular}


The beta value, measured in standard deviation units, is an indicator of the strength of the statistical relationship of each independent variable to the dependent variables. The results found that Features was the strongest predictor of usefulness and perceived quality, whereas Variety of Facilities was the weakest. However, Accessibility and Features were almost equally important for explaining the variation in Frequency of Visits.

\section{Discussion}

This study's results provide insightful information that could be used by policymakers, urban designers, and urban planners to help them make decisions that will effectively utilise limited land resources. The results suggest that users' attitudes and behaviours are influenced by their perceptions of the features, naturalness, accessibility, and variety of facilities. The results are consistent with previous studies regarding, for example, natural features (Coley et al., 1997), facilities (Bonnes et al., 2011; Kaczynski et al., 2008), and accessibility (Wang et al., 2015). However, no attributes about safety were elicited in this study, and it is commonly identified as an important UGS characteristics in prior studies. This may be explained by the relatively low crime rates in the city (United Nations - Habitat, 2012).

The two measures of attitudes were usefulness and perceived quality, which were most strongly predicted by the respondents' perceptions of UGS' features. Based on the results of the factor analysis, a nicely themed design, sufficient catering services, educational features (e.g. tree labels, exhibition gallery), aesthetic features (e.g. sculpture), and various events (e.g. flower show, Lunar New Year fairs) were the variables highly loaded in the features factor. The key design and management implications are discussed as follows.

- Identification of a UGS as a themed green space (an item in the features factor) is important because theme is part of the users' experience (Kevin KF Wong \& Cheung, 1999). Lukas (2007) suggested that a themed space creates a holistic and integrated organization of space resulting in a thematic experience. Two examples in Hong Kong are Sun Yat Sen Memorial Park, which is designed to commemorate Sun's contribution as the father of modern China, and Lingnan Garden in Lai Chi Kok Park, which is designed in traditional Chinese architectural style (Leisure and Cultural Services Department, 2014). These themed parks can be role models for other parks aiming for themed design.

- The features factor included catering services and a variety of events. As suggested by Grahn and Stigsdotter (2010), people enjoy festive events where they can eat, drink, and watch entertainment. Therefore, UGS management might consider increasing the catering 
options and availability and organising more events, such as flower shows, concerts, and so on. A specific location for street performances might increase the liveliness of UGS (Simpson, 2011).

- Another features item was educational opportunities, particularly for children. Exposure to UGS tends to stimulate the imagination and inventiveness (Zhou \& Parves Rana, 2012), which are desirable for intellectual advancement. Therefore, educational elements, such as educational tree labels and exhibition galleries, might be added to UGS to enhance their educational potential.

- The aesthetic aspects of features in UGS positively influenced the respondents' attitudes and behaviours. Parsons and Daniel (2002) suggested that environmental aesthetic elements might help people to form emotional attachments to each other and, therefore, strengthen place attachments and result in feelings of psychological comfort (Brown, Perkins, \& Brown, 2004; Hidalgo \& Hernandez, 2001). The aesthetic qualities of UGS could be improved by accentuating their natural features and by improving park maintenance, scenic views, and cleanliness (Giles-Corti et al., 2005; Thompson, 2002).

This study identified accessibility as a key concern for people when they visit UGS. This factor was more important to the frequency of visits to UGS than were features, naturalness, or variety of facilities. This result is generally consistent with Holman, Donovan, and Corti (1996) and Wang, Mateo-Babiano, and Brown (2013), who found that perceived accessibility influenced the frequency of use of urban open spaces. Although the accessibility construct may be conceptually similar to the idea that something is too geographically distant (Koon Kwai Wong, 2009), the present study operationalized accessibility to include hours of operation and price as well as locational convenience. As suggested by Van Herzele and Wiedemann (2003), prices and hours of operation are factors that influence the sense of attractiveness of UGS. In Hong Kong, the under-utilization of UGS has repeatedly been criticised in the media, by lawmakers, and by community members. For example, a report of the Audit Commission (2008) revealed that the use of sports facilities in UGS was less than $30 \%$. To encourage use of UGS, a greater understanding of the multi-dimensionality of accessibility should be developed, as suggested in the following points.

- According to the Leisure and Cultural Services Department (2014), some territorial and district UGS are open 24 hours a day; others open at about 6:00 am and close at about 11:00 pm. The relevant public authorities should study the use patterns of specific UGS to investigate users' desires relative to hours of operation. 
- Locational convenience is an aspect of accessibility that influences the frequency of visits. Although the Hong Kong planning authority has provided UGS at the neighbourhood level, these spaces are mostly small and of limited use. A. Y. Lo and Jim (2012) found that Hong Kong residents preferred large parks. Poudyal et al. (2009)'s results suggested that people are willing to trade UGS proximity for size. In Hong Kong, UGS at the neighbourhood level are generally proximate, but people continue to want conveniently located and large parks. Therefore, the locational convenience of large parks should be considered.

- In the RGT interviews, respondents suggested that the fees charged to use parks and open spaces influence the extent of their use. It was pointed out that sports facilities in public parks (e.g. tennis courts, swimming pools) are not free. Again, if authorities are interested in boosting public use of these spaces, they should consider reviewing and lowering the fees.

This study was limited in ways that can be addressed by future research. The first limitation is the small sample size of the telephonic survey and its selectivity of highly educated respondents, which over-represented the attitudes and behaviours of relatively well-educated people. Thus, future research could validate these results by replicating the analysis on a larger and more representative sample. Similarly, it may be that Hong Kong's UGS are unique and the results pertaining to them may or may not be generalizable to other cities or cultural contexts. Therefore, further research is needed to apply the model in different cultural and spatial contexts. Furthermore, all of the measures developed from the survey data were self-reports, which may bias the results. Last, the $\mathrm{R}^{2}$ value of frequency of visits to UGS was $16 \%$, which was low compared to the $\mathrm{R}^{2}$ values of usefulness and perceived quality (both of which exceeded 50\%). This suggests that there are other factors that predict the frequency of visits than were not accounted for in the within study that should be considered in future research. For example, in addition to psychological factors, socioeconomic and environmental factors may be explanatory. 


\section{Conclusions}

This study used the RGT technique to elicit key attributes of UGS by allowing respondents to produce personal propositions and psychological constructs that are often unarticulated and difficult to elaborate. The study filled a gap in the research literature by analytically considering the complexity of users' evaluative processes and focusing on psychological constructs. Through the data reduction process suggested by (Cammock et al., 1995), the respondents identified 26 characteristics of UGS in Hong Kong, a high-density city. These characteristics were statistically grouped into four key factors: features, naturalness, accessibility, and variety of facilities. The four factors were found to significantly predict users' attitudes regarding the usefulness and perceived quality of the green spaces and their behaviour measured as their frequency of visits to UGS. The results found that features of UGS were the strongest predictors of usefulness and perceived quality and the variety of facilities was the weakest. However, accessibility and features were almost equally important to explaining the variation in the frequency of visits to Hong Kong's green spaces.

The results of this study can support public authorities and urban planners as they strive to effectively design and provide UGS to meet users' needs. To generate the public's favourable attitudes towards UGS, policy makers and planners should provide tailored features, such as themed designs, ample catering services, educational opportunities, aesthetics, and a variety of events. In addition to features, accessibility should be reconceptualised to focus on increasing the frequency of visits to UGS. Accessibility should be viewed as a multi-dimensional concept that includes the extent of hours of operation and fees as well as locational proximity. Although UGS at the neighbourhood level are generally accessible to local residents, the relevant public authorities should consider the locational convenience of relatively larger parks. Further study of UGS use and a review of fees would identify users' preferred hours of use and their perceptions of reasonable prices. Adapting to these factors would likely increase the frequency of use and users would benefit with respect to restorative processes and quality of life. 


\section{References}

Audit Commission. (2008). Director of Audit's Report No.51. The Government of Hong Kong Special Administrative Region Retrieved from http://www.aud.gov.hk/eng/pubpr arpt/rpt 51.htm.

Balram, S., \& Dragićević, S. (2005). Attitudes toward urban green spaces: integrating questionnaire survey and collaborative GIS techniques to improve attitude measurements. Landscape and Urban planning, 71(2), 147-162.

Bedimo-Rung, A. L., Mowen, A. J., \& Cohen, D. A. (2005). The significance of parks to physical activity and public health: a conceptual model. American journal of preventive medicine, 28(2), 159-168.

Bonnes, M., Passafaro, P., \& Carrus, G. (2011). The ambivalence of attitudes toward urban green areas: Between proenvironmental worldviews and daily residential experience. Environment and Behavior, 43(2), 207-232.

Brown, B. B., Perkins, D. D., \& Brown, G. (2004). Incivilities, place attachment and crime: Block and individual effects. Journal of Environmental Psychology, 24(3), 359-371.

Burgess, J., Harrison, C. M., \& Limb, M. (1988). People, parks and the urban green: a study of popular meanings and values for open spaces in the city. Urban Studies, 25(6), 455-473.

Cammock, P., Nilakant, V., \& Dakin, S. (1995). Developing a lay model of managerial effectiveness: A social constructionist perspective. Journal of Management Studies, 32(4), 443-474.

Carr, S. (1992). Public space: Cambridge University Press.

Census and Statistics Department. (2011). 2011 Population Census. Hong Kong: The Government of Hong Kong Special Adminstrative Region Retrieved from http://www.census2011.gov.hk/en/index.html.

Chiesura, A. (2004). The role of urban parks for the sustainable city. Landscape and Urban planning, 68(1), 129-138.

Coles, R., \& Bussey, S. (2000). Urban forest landscapes in the UK-progressing the social agenda. Landscape and Urban planning, 52(2), 181-188.

Coley, R. L., Sullivan, W. C., \& Kuo, F. E. (1997). Where does community grow? The social context created by nature in urban public housing. Environment and Behavior, 29(4), 468-494.

Coshall, J. T. (2000). Measurement of tourists' images: The repertory grid approach. Journal of Travel Research, 39(1), 85-89.

Daniels, K., Johnson, G., \& de Chernatony, L. (2002). Task and institutional influences on managers' mental models of competition. Organization Studies, 23(1), 31-62. 
De Vries, S., Verheij, R. A., Groenewegen, P. P., \& Spreeuwenberg, P. (2003). Natural environments-healthy environments? An exploratory analysis of the relationship between greenspace and health. Environment and Planning A, 35(10), 1717-1732.

Field, A., Miles, J., \& Field, Z. (2012). Discovering Statistics Using SPSS: SAGE Publications.

Fransella, F., Bell, R., \& Bannister, D. (2004). A Manual for Repertory Grid Technique: Wiley.

Giles-Corti, B., Broomhall, M. H., Knuiman, M., Collins, C., Douglas, K., Ng, K., . . . Donovan, R. J. (2005). Increasing walking: how important is distance to, attractiveness, and size of public open space? American journal of preventive medicine, 28(2), 169-176.

Grahn, P. (1994). Green structures-The importance for health of nature areas and parks. European Regional Planning, 56, 89-112.

Grahn, P., \& Stigsdotter, U. K. (2010). The relation between perceived sensory dimensions of urban green space and stress restoration. Landscape and Urban planning, 94(3), 264-275.

Grove, J., Troy, A., O’Neil-Dunne, J., Burch Jr, W., Cadenasso, M., \& Pickett, S. (2006). Characterization of households and its implications for the vegetation of urban ecosystems. Ecosystems, 9(4), 578-597.

Hair, J. F., Black, W. C., Babin, B. J., \& Anderson, R. E. (2013). Multivariate Data Analysis: Pearson Education, Limited.

Hidalgo, M. C., \& Hernandez, B. (2001). Place attachment: Conceptual and empirical questions. Journal of Environmental Psychology, 21(3), 273-281.

Hillsdon, M., Panter, J., Foster, C., \& Jones, A. (2006). The relationship between access and quality of urban green space with population physical activity. Public health, 120(12), 1127-1132.

Holman, C., Donovan, R. J., \& Corti, B. (1996). Factors influencing the use of physical activity facilities: results from qualitative research.

Home, R., Bauer, N., \& Hunziker, M. (2010). Cultural and biological determinants in the evaluation of urban green spaces. Environment and Behavior, 42(4), 494-523.

Huang, X., Wright, R. P., Chiu, W. C., \& Wang, C. (2008). Relational schemas as sources of evaluation and misevaluation of leader-member exchanges: Some initial evidence. The Leadership Quarterly, 19(3), 266-282.

Hur, M., Nasar, J. L., \& Chun, B. (2010). Neighborhood satisfaction, physical and perceived naturalness and openness. Journal of Environmental Psychology, 30(1), 52-59.

Jankowicz, D. (2005). The Easy Guide to Repertory Grids: Wiley.

Jay, M., \& Schraml, U. (2009). Understanding the role of urban forests for migrants-uses, perception and integrative potential. Urban Forestry \& Urban Greening, 8(4), 
283-294.

Kaczynski, A. T., Potwarka, L. R., \& Saelens, B. E. (2008). Association of park size, distance, and features with physical activity in neighborhood parks. American journal of public health, 98(8), 1451.

Kaczynski, A. T., Potwarka, L. R., Smale, B. J., \& Havitz, M. E. (2009). Association of parkland proximity with neighborhood and park-based physical activity: variations by gender and age. Leisure sciences, 31(2), 174-191.

Kelly, G. (1955). The Psychology of Personal Constructs: A theory of personality: Routledge.

Lafortezza, R., Carrus, G., Sanesi, G., \& Davies, C. (2009). Benefits and well-being perceived by people visiting green spaces in periods of heat stress. Urban Forestry \& Urban Greening, 8(2), 97-108.

Lawton, L. J. (2005). Resident perceptions of tourist attractions on the Gold Coast of Australia. Journal of Travel Research, 44(2), 188-200.

Lee, A., \& Maheswaran, R. (2011). The health benefits of urban green spaces: a review of the evidence. Journal of Public Health, 33(2), 212-222.

Lee, C., \& Moudon, A. V. (2008). Neighbourhood design and physical activity. Building research \& information, 36(5), 395-411.

Leisure and Cultural Services Department. (2007). Public Pleasure Grounds - Venues. The Government of Hong Kong Special Adminstrative Region Retrieved from http://www.lcsd.gov.hk.

Leisure and Cultural Services Department. (2014). Leisure and Cultural Services Department. The Government of Hong Kong Special Administrative Region Retrieved from http://www.lcsd.gov.hk/en/ls_park.php.

Lo, A. Y., \& Jim, C. (2010). Willingness of residents to pay and motives for conservation of urban green spaces in the compact city of Hong Kong. Urban Forestry \& Urban Greening, 9(2), 113-120.

Lo, A. Y., \& Jim, C. (2012). Citizen attitude and expectation towards greenspace provision in compact urban milieu. Land Use Policy, 29(3), 577-586.

Lo, S., Yiu, C., \& Lo, A. (2003). An analysis of attributes affecting urban open space design and their environmental implications. Management of Environmental Quality: An International Journal, 14(5), 604-614.

Lukas, S. A. (2007). The themed space: Locating culture, nation, and self: Rowman \& Littlefield.

Luymes, D. T., \& Tamminga, K. (1995). Integrating public safety and use into planning urban greenways. Landscape and Urban planning, 33(1), 391-400.

Maruani, T., \& Amit-Cohen, I. (2007). Open space planning models: A review of approaches and methods. Landscape and Urban planning, 81(1), 1-13.

Olson, J. C., \& Muderrisoglu, A. (1979). The stability of responses obtained by free 
elicitation: Implications for measuring attribute salience and memory structure. Advances in consumer research, 6(1), 269-275.

Parsons, R., \& Daniel, T. C. (2002). Good looking: in defense of scenic landscape aesthetics. Landscape and Urban planning, 60(1), 43-56.

Pike, S. (2003). The use of repertory grid analysis to elicit salient short-break holiday destination attributes in New Zealand. Journal of Travel Research, 41(3), 315-319.

Planning Department. (2005). Hong Kong Planning Standards and Guidelines. Hong Kong: The Government of Hong Kong Special Adminstrative Region Retrieved from http://www.pland.gov.hk/pland_en/tech_doc/hkpsg/full/ch4/ch4 text.htm.

Planning Department. (2013). Land Utilization in Hong Kong The Government of Hong Kong Special Administrative Region: Retrieved from http://www.pland.gov.hk/pland_en/info_serv/statistic/landu.html.

Poudyal, N. C., Hodges, D. G., \& Merrett, C. D. (2009). A hedonic analysis of the demand for and benefits of urban recreation parks. Land Use Policy, 26(4), 975-983.

Reddy, P., \& Caputi, P. (1999). A comparison of triadic and dyadic methods of personal construct elicitation. Journal of Constructivist Psychology, 12(3), 253-264.

Reger, R. K. (1990). The repertory grid technique for eliciting the content and structure of cognitive constructive systems (pp. 301-309): John Wiley \& Sons Ltd., Chicester.

Sanesi, G., \& Chiarello, F. (2006). Residents and urban green spaces: the case of Bari. Urban Forestry \& Urban Greening, 4(3), 125-134.

Schipperijn, J., Bentsen, P., Troelsen, J., Toftager, M., \& Stigsdotter, U. K. (2013). Associations between physical activity and characteristics of urban green space. Urban Forestry \& Urban Greening, 12(1), 109-116.

Schipperijn, J., Ekholm, O., Stigsdotter, U. K., Toftager, M., Bentsen, P., Kamper-Jørgensen, F., \& Randrup, T. B. (2010). Factors influencing the use of green space: Results from a Danish national representative survey. Landscape and Urban planning, 95(3), 130-137.

Schipperijn, J., Stigsdotter, U. K., Randrup, T. B., \& Troelsen, J. (2010). Influences on the use of urban green space-A case study in Odense, Denmark. Urban Forestry \& Urban Greening, 9(1), 25-32.

Scott, M. M., Evenson, K. R., Cohen, D. A., \& Cox, C. E. (2007). Comparing perceived and objectively measured access to recreational facilities as predictors of physical activity in adolescent girls. Journal of Urban Health, 84(3), 346-359.

Shan, X.-Z. (2014). Socio-demographic variation in motives for visiting urban green spaces in a large Chinese city. Habitat International, 41, 114-120.

Simpson, P. (2011). Street performance and the city: Public space, sociality, and intervening in the everyday. Space and Culture, 1206331211412270.

Tan, F. B., \& Hunter, M. G. (2002). The repertory grid technique: A method for the study of 
cognition in information systems. Mis Quarterly, 39-57.

Tan, P. Y., Wang, J., \& Sia, A. (2013). Perspectives on five decades of the urban greening of Singapore. Cities, 32, 24-32.

Tang, B.-s., \& Wong, S.-w. (2008). A longitudinal study of open space zoning and development in Hong Kong. Landscape and Urban planning, 87(4), 258-268.

Tang, B.-s., Wong, S.-w., \& Lee, A. K.-w. (2007). Green belt in a compact city: A zone for conservation or transition? Landscape and Urban planning, 79(3), 358-373.

Thompson, C. W. (2002). Urban open space in the 21st century. Landscape and Urban planning, 60(2), 59-72.

United Nations - Habitat. (2012). Enhancing Urban Safety and Security: Global Report on Human Settlements 2007: Taylor \& Francis.

Van den Berg, A. E., \& Ter Heijne, M. (2005). Fear versus fascination: An exploration of emotional responses to natural threats. Journal of Environmental Psychology, 25(3), 261-272.

Van Herzele, A., \& Wiedemann, T. (2003). A monitoring tool for the provision of accessible and attractive urban green spaces. Landscape and Urban planning, 63(2), 109-126.

Wang, D., Brown, G., Liu, Y., \& Mateo-Babiano, I. (2015). A comparison of perceived and geographic access to predict urban park use. Cities, 42, 85-96.

Wang, D., Mateo-Babiano, I., \& Brown, G. (2013). Rethinking Accessibility in Planning of Urban Open Space Using an Integrative Theoretical Framework. Paper presented at the SOAC 2013: 6th State of Australian Cities Conference.

Wong, K. K. (2009). Urban park visiting habits and leisure activities of residents in Hong Kong, China. Managing Leisure, 14(2), 125-140.

Wong, K. K., \& Cheung, P. W. (1999). Strategic theming in theme park marketing. Journal of Vacation Marketing, 5(4), 319-332.

Wright, R. P. (2008). Eliciting cognitions of strategizing using advanced repertory grids in a world constructed and reconstructed. Organizational Research Methods, 11(4), 753-769.

Ye, S. (1998). The land resource and landuse of Hong Kong. Chinese Geographical Science, $8(1), 12-24$.

Zhou, X., \& Parves Rana, M. (2012). Social benefits of urban green space: A conceptual framework of valuation and accessibility measurements. Management of Environmental Quality: An International Journal, 23(2), 173-189. 


\section{Appendix 1 - Questionnaire Items}

Constructs elicited from RGT

- The urban green spaces provide facilities for all weather conditions.

- The urban green spaces provide wide range of facilities.

- The urban green spaces provide sufficient ancillary facilities. (e.g. drinking, washroom)

- The urban green spaces provide green areas and features (e.g. trees, grass, etc).

- The air quality is good in the urban green spaces.

- There are sufficient spaces in the urban green spaces. (not crowded)

- There are clear divisions of areas for various activities in the urban green spaces.

- The urban green spaces provide natural environment.

- The urban green spaces provide sufficient catering services.

- The facilities management in the urban green spaces is good.

- The urban green spaces create peaceful and quiet feeling.

- The urban green spaces provide beautiful scenic view.

- There are aesthetic features in the urban green spaces (e.g. sculpture).

- The urban green spaces allow free movement.

- The urban green spaces provide sufficient seating.

- The urban green spaces are accessible through the public transportation.

- The urban green spaces provide barrier free facilities for elderly / disabled persons.

- There are no pests in the urban green spaces.

- The urban green spaces have nice themed design.

- There are educational features in the urban green spaces (e.g. tree labels, exhibition gallery).

- Various events are organized in the urban green spaces (e.g. flower show, Lunar New Year fairs).

- The urban green spaces provide facilities for specific interests.

- The urban green spaces are conveniently located near my home.

- The opening hours of the urban green spaces are convenient.

- The facilities in the urban green spaces are free of charges.

- There are booking system for sports facilities in the urban green spaces.

Usefulness (Balram and Dragićević, 2005)

- I use the urban green spaces to relax.

- I use the urban green spaces for recreation.

- The urban green spaces contribute to my quality of life.

- The urban green spaces would increase my property value.

Perceived quality (Bonnes et al., 2011)

- There are urban green spaces where children can play freely.

- There are enough public urban green spaces.

- The urban green spaces are in good condition.

- The urban green spaces are well-equipped.

- Most urban green spaces are closed to the public.

Visit Frequency (Schipperijn et al., 2010)

- I have often used urban open spaces in the past 4 weeks.

- I have been using urban open spaces regularly in the past 4 weeks. 